\title{
Online education during COVID-19: perception of academic stress and emotional intelligence coping strategies among college students
}

\author{
Yamini Chandra \\ School of Commerce, Narsee Monjee Institute of Management Studies, \\ Mumbai, India
}

\begin{abstract}
Purpose - Due to COVID-19 pandemic, the government around the world has closed all the educational institutions to control the spread of disease, which is creating a direct impact on students, educators and institutions. The sudden shift from the physical classroom to virtual space is creating a disruption among students. The purpose of this study was to analyze the perception of academic stress experienced by students during current online education and coping strategies using emotional intelligence adopted by them.

Design/methodology/approach - Using a purposive sampling method, data were collected on a sample of 94 students pursuing undergraduation and postgraduation from two Indian cities, Ahmedabad, and Mumbai. The survey was conducted using two online questionnaires, Perceptions of Academic Stress Scale and Emotional Intelligence Scale and analyzed using descriptive statistics with chi-square analysis. A telephonic discussion was also conducted with some respondents to understand different coping strategies used by them to handle the stress.

Findings - The findings indicated significant differences were observed between the fear of academic failure and online and home environment among male and female students. Many of them have started diverting themselves to various creative activities and taking up courses that are helping them to learn new technical skills. By using emotional intelligence and distancing from boredom and depressive thoughts, students were trying to cope with negative effects arising from the current pandemic situation.

Research limitations/implications - This research study will be beneficial to educators, scholars, students, parents and will add a contribution to its field. However, the key factors studied were limited to a small sample from selected institutions and cities, which cannot be used to generalize to a large population.

Practical implications - The findings of this paper will be useful to assess the key challenges of online education especially at the time when it is the only option.

Social implications - The findings of this paper will be beneficial to understand the academic stress experienced by students and how a cultural and educational modification will be implemented.

Originality/value - This research study was conducted during the lockdown in India (April-May 2020), and the results derived through it are original in nature.
\end{abstract}

Keywords Academic stress, COVID-19, Emotional intelligence, Online education

Paper type Research paper

\section{Introduction}

The coronavirus disease (COVID-19) [1] is a health crisis that has completely changed the lives and perspectives of all people. The COVID-19 was first identified in December 2019 in Wuhan, the capital of China's Hubei province. Since then, it has spread globally resulting in the ongoing 2019-20 coronavirus pandemic (Hui et al., 2020, p. 264) (as seen in Ilmiyah and Setiawan, 2020). The government around the world has closed all the educational institutions, to control the spread of disease, considering the safety of students, educators and all associated people. There is a severe short-term disruption that has been felt by families across the globe. Home education has brought a lot of shocks not only to students but also to their parents' productivity (Burges and Sievertsen, 2020). As now teaching has moved from physical to virtual classrooms at "untested and unprecedented" level (Burges and Sievertsen,

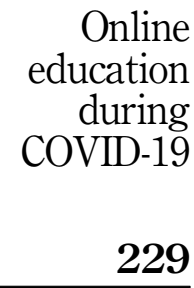

Received 21 May 2020 Revised 17 August 2020 Accepted 31 August 2020 
AEDS

10,2
2020), parents have to spend more time monitoring their children and motivating them to continue education. Across the globe, this closure is impacting more than $90 \%$ of the world's student population, of which India itself is observing 34,337,594 affected learners (this number only includes learners enrolled in tertiary education in Indian universities, as on May 03, 2020) [2].

Globally over $1.2 \mathrm{bn}$ children are affected due to COVID-19 and are currently taking education remotely using digital platforms. To help institutions overcome this unexpected crisis, UNESCO is working with ministries of education across nations to ensure continued learning of students using different alternative channels and supporting them in various ways by technical assistance, selection of digital learning tools, arranging webinars and creation of national learning platforms [3]. A report by the World Economic Forum (Li and Lalani, 2020) observed that online learning in today's time has increased students' retention and grasping information at a faster pace. Many educational institutions, government organizations and technology-led start-ups have introduced online courses (many of which are free and some have a very minimal fee) which is helping students and educators to temporarily cope with stress which is evolving due to lockdown and shutdown of all workspaces. One such is Byju's, a Bangalore, India-based digital educational platform founded and started by ByjuRaveendran, who has announced to give free access to children from its learning app (Lewis, 2020) [4].

Researchers, educators across the globe are trying their best to come up with more enhanced learning techniques based on the current situation, one of its types is designed by Ilmiyah and Setiawan (2020) which is a "student worksheet", to guide distance learning based on scientific literacy indicators in the COVID-19 topic. Researchers in the past have also employed self-efficacy instruments in various academic and technology-related courses and observed that it has a positive influence on students' achievement and persistence in specific tasks (Puzziferro, 2008, p. 73). A report by Bullen (1990) quoted that Utopian possibilities of classroom instructions using technology-based instruction have further observed distance learning's practical implications as a supplement to enhance learning (p. 30) (seen in Phipps and Merisotis, 1999). Some have even observed that academic leaders report that their faculties "accept the value and legitimacy of online education" (Allen and Seaman, 2016).

Imparting education using online mode has started with the advent of the Internet since the 1990s. Initially, the aim was to test the acquisition of transferable skills in communication and information technology (using computer-aided learning) (Volery and Lord, 2000). E-learning, online learning, web-based learning, internet-based learning or computer-assisted learning are terms that are interchangeably used for this type of learning ways (Ruiz et al., 2006). The rapid expansion and use of the Internet and easily available platforms have made educational institutions reaching out and delivering education to students spread geographically. Online learning, distance education and remote learning is nothing new to us. The only difference is now it has taken the only source of education due to the social distancing and nationwide lockdown amidst COVID-19 pandemic.

The COVID-19 pandemic is accompanied with strictly following isolation measures that have led learners and educators to confine at their homes; a disturbing social life and learning at isolation has made it stressful for students and educators. The mere essence of group learning, group classroom activities are being missed by both educators and students. All this has led to an experience of stress by both students and educators. Low physical activity and spending all time at home are creating its negative impact, which all of us are trying to overcome using a lot of other activities to cope with this condition.

Academic stress emerges out from experiencing stress due to factors such as scholarship requirements, family-related pressures, competition in the class and course-related stress and financial burdens, (Misra and Castillo, 2004, p. 133) experienced by students. For some students, it can also be due to migrating at different places, learning different cultural values 
and language in addition to getting adjusted to academic requirements (Mori, 2000; Essandoh, 1995). Students always live under the pressure to perform better than their peers. They are continuously compared with siblings and other children/kids of their age by their parents, teachers, friends, etc. This always leads to a situation making these children confused and under constant pressure to perform better, achieve better grades, excel well in extracurricular activities, take up hobby classes and what not. Many times, it has been observed that parents put these undue pressures to satisfy their unmet needs which they were not able to fulfill due to personal reasons. Teens nowadays experience peer pressure of involving themselves in many activities apart from academic involvement, so that their peers can welcome them in their groups. As students experience a high level of stress arising from unprecedented academic pressure, most of them report experiencing low self-esteem, a poor concentration that has its impact on their academic performance. The perception of academic stress is creating a very negative impact on their well-being, their decision to choose career options, sleeping difficulties, psychosomatic complaints, worrying about future, comorbid conditions like anxiety and depression, inability to manage course workload, etc. (Bedewy and Gabriel, 2015; Acharya, 2003; Iqbal et al., 2015). The perception of the academic stress scale used in this study was developed on 100 students (men and women) with the age range of 19-26 yrs, pursuing the third year in educational psychology at Tanta University, Egypt. This scale overall observed students' confidence in their academic performance and their ability to succeed academically.

Emotional intelligence is an emerging topic for educational, psychological and management studies. The concept is rooted in the understanding of emotions of self, helping oneself to direct the emotional reactions and labeling the experiences of different emotions and helping others to understand and help people to channelize their emotions (Bliss, 2005). It also refers to tackling emotional upsets, adapting ways and capacity to avoid emotional exhaustion such as stress, emotional self-control, burnout and learning to avoid the negativity of emotions and handling egoism (Sala, 2002; Chandra and Mathur, 2016, p. 231). The emotional intelligence scale used in this study was developed by Hyde et al. (2002), first administered on a sample of 200 Indian executives. The scale originally had 106 items, but after statistical analysis, only 34 items were included in the final version. The scores assess individuals on "above average emotionally intelligent", "below average emotionally intelligent" and "average emotionally intelligent" (Suleman et al., 2019; Hyde et al., 2002). During their elementary years of education, students were given a lot of exercises which helps them to understand and become aware of their own emotions and practical applications which help them to channelize their emotions in more constructive ways. Students are observed to practice self-awareness, indulging in value-driven activities, empathy and assertive and altruistic work behavior. A lot of academic activities like group projects, team activities, role plays, etc. help them to develop all these along with their academic achievement.

\section{The objective of the study}

This study was conducted to understand and analyze the perception of academic stress as experienced by students (from higher educational institutions) and coping strategies using their emotional intelligence during the current COVID-19 pandemic. The disturbed education because of the sudden lockdown has made it very difficult for educational institutions, educators, students and their families and creating a negative impact on their personal, emotional, social and financial well-being. The objectives of the study are:

To analyze the experience of academic stress experienced by students arising due to online education. 
AEDS

10,2
To analyze the coping strategies using emotional intelligence by students to overcome academic stress.

To analyze the significant effects of academic stress and emotional intelligence on students (male and female) and other background variables such as a history of academic failure, current online education and current home environment.

\section{2}

\section{Methodology}

Sample, procedure, and data collection

Using a purposive sampling technique (Kothari, 2009), the researcher approached a large number of a heterogeneous group of students pursuing graduation and post-graduation from different management schools in India. An email explaining the objective of the study was sent to each prospective applicant; after seeking their willingness to participate, the online questionnaire was shared with them. However, after repeated follow-ups, 94 students have responded with their filled responses and were included in the study. A telephonic discussion was also carried out by researchers with respondents to discuss various ways adopted by them to cope with academic stress. The data were collected during the lockdown in India (April-May 2020).

\section{Tools used for data collection:}

Perceptions of Academic Stress Scale (PAS) (Bedewy and Gabriel, 2015, p. 4) is an 18-item, five-point Likert-type scale to measure perceptions, academic stress and its sources in students. This scale was standardized on students pursuing undergraduation and postgraduation. The responses ranged from $(1=$ strongly disagree to $5=$ strongly agree) measuring four dimensions with internal consistency; these dimensions are as follows: pressures to perform (0.6), perceptions of workload and examinations (0.6), self-perceptions (0.5) and time constraints (0.6). The overall internal consistency reliability was 0.7 , with high scores indicating higher stress experienced by students (Bedewy and Gabriel, 2015, p. 5).

Emotional Intelligence Scale (EIS) (Hyde et al., 2002) is a 32-item, five-point Likert-type scale to measure emotional intelligence among people. The responses ranged from $(1=$ strongly disagree to $5=$ strongly agree) measuring ten dimensions which are selfawareness, empathy, self-motivation, emotional stability, managing relations, integrity, selfdevelopment, value orientation, commitment and altruistic behavior. The split-half reliability coefficient of the scale was found to be 0.88 ; reliability content was 0.93 (as seen in Uzzaman and Karim, 2017). A high score indicates that a person can balance personal and emotional life.

\section{Results}

This section depicts the results of the statistical analysis carried out on the collected data.

Table 1 represents the demographic profile of respondents in proportion to male $(n=56)$ $(56.4 \%)$ and female $(n=44)(43.6 \%)$ with age ranging from 18 to 24 years (mean $=21$ years); pursuing undergraduation $(n=79)(84 \%)$, postgraduation $(n=15)(16 \%)$ and were representing different Indian regions as eastern $(n=4)(4.3 \%)$, western $(n=71)(75.5 \%)$, northern $(n=18)(19.1 \%)$ and southern $(n=1)(1.1 \%)$ regions. The students were asked about other variables, such as (1) history of their academic failure, wherein $85.1 \%$ of students responded with "never", while $14.9 \%$ responded with experience of failing academically more than once. While the response on (2) satisfaction with the current online learning environment, it was observed that $58.5 \%$ of students have responded with their dissatisfaction and $41.5 \%$ of students have responded with their satisfaction with the current online learning environment. Furthermore, when asked about their satisfaction with 
the current home environment, $85.1 \%$ of students responded with their satisfaction, while $14.9 \%$ responded with dissatisfaction with the current home environment.

Table 2 represents the descriptive analysis on both the scales, for the analysis of PAS it was observed that the values for mean $=58.2$, median $=57.0, \mathrm{SD}=6.88$, skewness $=-0.036112$ and kurtosis value was observed to be 0.111184 . For the EIS scale, the calculated values were mean $=113.43$, median $=113, \mathrm{SD}=11.76$, skewness $=0.180648$, and kurtosis value was observed to be -0.138646 .

Table 3 represents the chi-square value to find out the effect and the differences of history of academic failure (never failed or failed more than once) on male and female students. It was observed that overall male students have reported a high score (107.3) for the factor "failed in the past more than once" compared with female students (135.2), whereas for the factor "never failed", female students were observed to scored higher (23.1) compared with their counterparts (19.0). The calculated chi-square value was observed to be $X^{2}$ $(1, N=94)=285.53, p=0.00001$ (Sig. $p<0.5)$, whereas the chi-square statistic with Yates correction was observed to be $X^{2}(1, N=94)=284.79, p=0.00001$ (Sig. $\left.p<0.5\right)$.

Table 4 represents the chi-square analysis of the factor "satisfaction with the current online learning environment" on male and female students. It was observed that overall male

\begin{tabular}{llcr}
\hline Criterion groups & Levels & Data in numbers & Frequency \\
\hline \multirow{2}{*}{ Gender } & Female & 41 & 43.6 \\
& Male & 53 & 56.4 \\
Education (currently pursuing) & Undergraduate & 79 & 84.0 \\
Geographical representation of Indian regions & Post-Graduate & 15 & 16.0 \\
& Eastern & 04 & 4.3 \\
& Western & 71 & 75.5 \\
History of academic failure & Northern & 18 & 19.1 \\
Satisfaction with the current online learning environment & Southern & 01 & 01.1 \\
Satisfaction with the current home environment & Never & 80 & 85.1 \\
& More than once & 14 & 14.9 \\
& Yes & 55 & 58.5 \\
& No & 14 & 41.5 \\
\end{tabular}

\section{Online education during \\ COVID-19}

233

\begin{tabular}{lcr}
\hline Calculated values & PAS & EIS \\
\cline { 1 - 2 } Frequency count & 94 & 94 \\
Mean & 3.276 & 3.904 \\
Standard deviation (SD) & 1.120 & 0.855 \\
Standard error & 0.061 & 0.232 \\
Skewness & -0.71 & -0.582 \\
Kurtosis & 2.960 & 3.153 Analysis of descriptive \\
& & statistics $(N=94)$ \\
\hline
\end{tabular}

\begin{tabular}{lccrr}
\hline Criterion groups & Category 1 male & Category 2 female & Marginal row totals & \\
\cline { 1 - 3 } Group 1 (never failed) & $7252(7633.1)[19.0]$ & $6437(6055.9)[23.1]$ & 13689 & Chi-square analyses on \\
Group 2 (failed more than once) & $1735(1353.9)[107.3]$ & $693(1074.1)[135.2]$ & 2428 & academic \\
Marginal column totals & 8987 & 7130 & 16117 (grand total) & failure $(N=94)$ \\
\hline
\end{tabular}


AEDS 10,2

\section{4}

Table 4. current online learning environment $(N=94)$
Chi-square analyses on

students have reported high scores on their experience of dissatisfaction with the current online learning environment (0.18) compared with female students (0.2), whereas, an equal score was observed related to expressing satisfaction with the current online learning environment reported by both male and female students. The calculated chi-square value was observed to be $X^{2}(1, N=94)=1.01, p=0.316087$ (Non-Sig. $\left.p<0.5\right)$, whereas the chi-square statistic with Yates correction was observed to be $X^{2}(1, N=94)=0.9731, p=0.323918$ (NonSig. $p<0.5)$.

Table 5 represents the chi-square analysis to find out the "satisfaction with current home environment" on male and female students. It was observed that overall female students have reported high scores on expressing their dissatisfaction with the home environment (81.2), compared with the male students (64.4), whereas, while expressing their satisfaction, 13.6 female students reported a high score compared with male students (10.8). The calculated chisquare value was observed to be $X^{2}(1, N=94)=170.03, p=0.00001$ (significant at $p<0.5$ ), whereas, chi-square statistic with Yates correction was observed to be $X^{2}$ $(1, N=94)=169.44, p=0.00001$ (Sig. $p<0.5)$.

Table 6 represents the chi-square analysis on gender (male; female) and pursuing current education (undergraduation; postgraduation) on the PAS scale. With relation to stress, no significant differences were observed between the students pursuing graduation and postgraduation. The calculated chi-square value was observed to be $X^{2}(1, N=94)=0.3093$, $p=0.578105$ (Non-sig. $p<0.5)$ and $X^{2}(1, N=94)=0.2696, p=0.603614$ (Non-Sig. $p<0.5$ ) (chi-square statistic with Yates correction).

Table 7 represents the chi-square analysis on gender (male; female) and pursuing current education (under graduation; post-graduation) using the EIS. It was observed that, from the group of under graduation, female students have reported high score (1.32) compared with male students (1.01), whereas the group pursuing postgraduation showed similar observation; here also female students have reported high score (7.17), compared with male students (5.48). The calculated chi-square value was observed to be $X^{2}$ $(1, N=94)=14.99, p=0.000108$ (Sig. $p<0.5)$, whereas the chi-square statistic with Yates correction was observed to be $X^{2}(1, N=94)=14.7795, p=0.000121$ (Sig. $p<0.5$ ).

\begin{tabular}{lccc}
\hline Criterion groups & Category 1 male & Category 2 female & Marginal row totals \\
\hline Group 1 (No) & $5226(5257.1)[0.18]$ & $4202(4170.9)[0.2]$ & 9428 \\
Group 2 (Yes) & $3761(3729.9)[0.3]$ & $2928(2959.2)[0.3]$ & 6689 \\
Marginal column totals & 8987 & 7130 & 16117 (Grand total) \\
\hline
\end{tabular}

\section{Table 5.}

Chi-square analyses on the current home

\begin{tabular}{lccc}
\hline Criterion groups & Category 1 male & Category 2 female & Marginal row totals \\
\hline Group 1 (No) & $1002(1290.3)[64.4]$ & $1312(1023.7)[81.2]$ & 2314 \\
Group 2 (Yes) & 7985 (7696.7) [10.8] & $5818(6106.3)[13.6]$ & 13803 \\
Marginal column totals & 8987 & 7130 & 16117 (Grand total) \\
\hline
\end{tabular}

\section{Table 6.}

Chi-square analyses on PAS scale for the factors, gender and pursuing education $(N=94)$

\begin{tabular}{lccc}
\hline Criterion groups & Category 1 undergraduate & Category 2 post-graduate & Marginal row totals \\
\hline Group 1 (male) & $2462(2469.5)[0.02]$ & $482(474.5)[0.12]$ & 2944 \\
Group 2 (female) & $2113(2105.5)[0.03]$ & $397(404.5)[0.14]$ & 2510 \\
Marginal column totals & 4575 & 879 & 5454 (Grand Total)
\end{tabular}




\section{Discussions of the analyzed data}

The current lives of all students, educators and families have observed a complete disruption due to nationwide lockdown and social distancing as a preventive precautionary measure taken for COVID-19. This has made everyone stay away from the place where they used to spend a maximum of their time (viz. schools, colleges, workplaces). Students are terribly missing their schools, college campuses, their friends, visiting the library, working in laboratories, working in group assignments projects, etc. Though in earlier times, these would have sounded nothing special, today (with the current situation) this reminds students of their good old times. Some researchers concluded that distance education was observed as better than campus-based education and came across as positive student-faculty attitudes (Bullen, 1990, p. 112). While some scholars have observed that "students always experience academic pressure as the biggest stress in their lives" (China Youth Social Service Center, 2008) and most of them experience stress related to pressure from transitional examinations, study workload (Liu and Tein, 2005; Zhang et al., 2001; Li and Zhang, 2008; as seen in Truc et al., 2015, para. 2, p. 3), not able to achieve better in exams and not able to live up to parents and teachers' expectations. And all these lead to experiencing feelings of stress and burnout among students.

As a precautionary and only source of measure to break the chain of COVID-19 pandemic, the government had to implement sudden lockdown and compulsory social distancing among people. This has led to another scenario wherein authorities are required to take immediate action to continue educating and evaluating students using virtual or online mode, taking special care that all this should not have any adverse impact on their studies. Many countries are trying to quickly provide access to digital learning content using multiple sources [5], however, the challenges emerging out of this new arrangement (and the only source as of now) has led educators to come up with more impactful online education. The classes now are being conducted using digital platforms, some have canceled exams, some have postponed and many institutions have adopted other alternate ways to evaluate students. Some students' careers might benefit from this disruption, but many bright and deserving students are finding it difficult to miss an opportunity to showcase their knowledge and score better grades through their performance in exams. All this has also presented us with a newer and alternate perception of our education system. But this also comes with a challenge that how the switch off from digital learning to traditional classroom learning will take place once the lives will get back as earlier. This will have a tremendous impact on all of us. Teachers, educators have more challenges; they need to switch playing a role from educator to intellect-on-stage mentor.

Going ahead, a further step was taken to understand the unique coping strategies adopted by students; a telephonic conversation was carried out on randomly selected 15 respondents, where they shared how they are coping with the academic stress emerging out of the current scenario. Some respondents narrated that they are trying to get focus using other alternate ways by engaging themselves to take up some online courses (to get more and diverse technical skills), "my writing skills are improving, I am learning digital marketing and I know this will be very helpful for my next academic section", said one student who has planned to take up admission for MBA in next academic year. "I am helping my father updating the software on payments and finishing off the entry of pending vouchers, helping him

\begin{tabular}{lccc}
\hline Criterion groups & Category 1 undergraduate & Category 2 post-graduate & Marginal row totals \\
\hline Group 1 (male) & 5031 (5102.8) [1.01] & $1012(940.2)[5.48]$ & 6043 \\
Group 2 (female) & $3973(3901.2)[1.32]$ & $647(718.8)[7.17]$ & 4620 \\
Marginal column totals & 9004 & 1656 & 10663 (Grand total)
\end{tabular}

\section{Online education during \\ COVID-19}

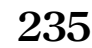

Table 7.

Chi-square analyses on emotional intelligence scale for the factors, gender and pursuing education $(N=94)$ 
AEDS

10,2 scheduling zoom calls with NGO regarding food donation drive upcoming for next week," said another student who was helping her father in his family business. Some have said they are taking a lot of creative activities and started to learn new hobbies (like music, painting, scripting, cooking, etc.), "my mother as happy as I am now helping her doing the household chores and now she has less complaint about me", said another student as she has started helping her mother in household chores, teaching math to his younger sibling. Some have even started a voluntary internship (working from home) with firms. "I improved my listening and learning skills, I learned to patiently listen to my mentor and how the customer problems are addressed. As the internship is online and not face to face, it takes time to comprehend things. The internship starts at $10.00 \mathrm{am}$, but because there is no one to supervise, I sometimes start late, but I am enjoying my work", said another student. All these activities (but not limited to)are giving them exposure to the world of work but also giving a sense of achievement and being a part of an organization that in itself is motivating for many students and is helping them increase their productivity. In another way, this can be referred to as using their emotional intelligence and diverting boredom and depressive thoughts students were trying to cope with the current pandemic situation. Some students even said that they were not able to save themselves and got lured with the Internet and end up spending most of their time on social media, e-connecting with others, which according to them is another way to cope with academic stress.

\section{Conclusion}

Students all over the globe experience stress arising out of many academic as well as nonacademic aspects such as environmental, socio-cultural and psychological factors. Stress arises in a way to perform better than peers, to live up to the expectations of parents, teachers, to score better grades which will help to get a dream job. All these put heavy pressure on students leading to a feeling of burnout arising from academic stress, while emotional development starts right from childhood and it affects children in many ways, developing ego concept and his/her emotional and social development. Children also develop emotional intelligence while observing their environment, teachers, peers, parents, siblings and developing an attachment with them (Suess et al., 1992). But what is missing which probably we have realized while going through the current situation, is that from now onwards, we need to teach our children to develop their emotional intelligence following social distancing and keeping away from each other physically, but not psychologically. With the advancement in the field of information technology, this can be practiced. It was observed that respondents were able to "reduce negative and unexpected emotional outbursts" (Uzzaman and Karim, 2017) and were able to divert it into different activities knowingly or unknowingly, which is one of the coping strategies adopted by students.

\section{Limitations}

This study was conducted on a smaller sample of students pursuing an undergraduate and post-graduate degree in management from two cities of India, using limited variables and tools, and hence the results cannot be generalized to a larger population.

\section{Significance and implications}

This study would be helpful to teachers, educators, institutional management, students and parents to understand the effect of the current online learning environment and its impact on the current education of students. Experts will be able to derive more comprehensive information and then can be used to broaden the scope of the study.

Note: This paper is presented in National Webinar on "Individual and Organizational Strategies to deal with Stress Issues during Corona phase", organized by the Department of 
Applied Psychology, IGNTU, Amarkantak (MP) in collaboration with Society for Industrial and Organizational Psychology, Varanasi on May 26, 2020.

\section{Notes}

1. World Health Organization. Coronavirus disease (COVID-19) outbreak (https://www.who.int) retrieved as on April 30, 2020.

2. UNESCO. COVID-19 Educational Disruption and Response. (https://en.unesco.org/covid19/ educationresponse) retrieved as on May 03, 2020.

3. UNESCO. UNESCO's support: Educational response to COVID-19. (www.en.unesco.org/covid19/ education)retrieved as on May 03, 2020.

4. CNN Business. Coronavirus lockdown could give online education a lasting boost in India. (https:// edition.cnn.com/2020/04/08/tech/online-education-india-coronavirus-spc/index.html) retrieved as on April 30, 2020.

5. World Bank. Remote Learning, EdTech and COCID-19. (https:/www.worldbank.org/en/topic/ edutech/brief/edtech-covid-19) retrieved as on April 30, 2020.

\section{References}

Acharya, S. (2003), "Factors affecting stress among Indian dental students", Journal of Dental Education, Vol. 67, pp. 1140-1148.

Allen, I.E. and Seaman, J. (2016), Online Report Card: Tracking Online Education in the United States. Babson Survey Research Group, Babson College, 231 Forest Street, Babson Park, MA 02457.

Bedewy, D. and Gabriel, A. (2015), "Examining perceptions of academic stress and its sources among university students: the perception of academic stress scale”, Health Psychology Open, Vol. 2 No. 2, 2055102915596714.

Bliss, S.E. (2005), "The affect of emotional intelligence on a modern organizational leader's ability to make effective decisions", (accessed 12 January 2012).

Bullen, M. (1990), "Learner responses to television in distance education: the need for a qualitative approach to research", in Clough, B. (Ed.), Proceedings of the Ninth Annual Conference of the Canadian Association for the Study of Adult Education, University of Victoria, Victoria, BC, pp. 48-53.

Burges, S. and Sievertsen, H.H. (2020), Schools, Skills, and Learning: The Impact of COVID-19 on Education, CEPR Policy Portal, Published: 01 April 2020, available at: https://voxeu.org/article/ impact-covid-19-education (accessed 30 April 2020).

Chandra, Y. and Mathur, K. (2016), "Perception of entrepreneurial orientation, aspiration, and its impact on emotional wellbeing: challenges for the future entrepreneurs", Research Trends in Economics, Finance, and Human Resource Management, Nirma University, pp. 227-237.

China Youth Social Service Center (2008), "2007 China national juvenile internet use survey report", available at: http://news.qq.com/a/20081020/001953.htm.

Essandoh, P.K. (1995), “Counseling issues with African college students”, The Counseling Psychologist, Vol. 23, pp. 348-360.

Hui, D.S., Azhar, E.I., Madani, T.A., Ntoumi, F., Kock, R. and Dar, O. (2020), "The continuing 2019$\mathrm{nCoV}$ epidemic threat of novel coronaviruses to global health - the latest 2019 novel coronavirus outbreak in Wuhan, China”, International Journal of Infectious Diseases, Vol. 91 January 14, pp. 264-6.

Hyde, A.S., Pethe, S. and Dhar, U. (2002), Emotional Intelligence Scale, Vedant Publications, Lucknow.

Ilmiyah, S. and Setiawan, A.R. (2020), "Students' worksheet for distance learning based on scientific literacy in the topic coronavirus disease 2019 (COVID-19)". doi: 10.31237/osf.io/fpg4j.

Iqbal, S., Gupta, S. and Venkatarao, E. (2015), "Stress, anxiety and depression among medical undergraduate students and their socio-demographic correlates", Indian Journal of Medical Research, Vol. 141 No. 3, pp. 354-357. 
AEDS 10,2

\section{8}

Kothari, C.R. (2009), Research Methodology: Methods and Techniques, 2nd Revised ed., New Age International Publishers, New Delhi, pp. 14-72.

Lewis, N. (2020), "Coronavirus lockdown could give online education a lasting boost in India", Published: April 08, 2020, available at: https://edition.cnn.com/2020/04/08/tech/online-educationindia-coronavirus-spc/index.html (accessed 3 May 2020).

Li, C. and Lalani, F. (2020), "The COVID-19 pandemic has changed education forever", This is how. World Economic Forum published: April 29, 2020, available at: https://www.weforum.org/agenda/ 2020/04/coronavirus-education-global-covid19-online-digital-learning/ (accessed 3 May 2020).

Li, H. and Zhang, Y. (2008), "Factors predicting rural Chinese adolescents' anxieties, fears, and depression”, School Psychology International, Vol. 29, pp. 376-384.

Liu, X. and Tein, J.Y. (2005), "Life events, psychopathology, and suicidal behavior in Chinese adolescents", Journal of Affective Disorders, Vol. 86, pp. 195-203.

Misra, R. and Castillo, L.G. (2004), "Academic stress among college students: comparison of American and international students", International Journal of Stress Management, Vol. 11 No. 2, p. 132.

Mori, S.C. (2000), "Addressing the mental health concerns of international students", Journal of Counselling and Development, Vol. 78, pp. 137-144.

Phipps, R. and Merisotis, J. (1999), "What's the difference? a review of contemporary research on the effectiveness of distance learning in higher education".

Puzziferro, M. (2008), "Online technologies self-efficacy and self-regulated learning as predictors of final grade and satisfaction in college-level online courses", The American Journal of Distance Education, Vol. 22 No. 2, pp. 72-89.

Ruiz, J.G., Mintzer, M.J. and Leipzig, R.M. (2006), "The impact of e-learning in medical education”, Academic Medicine, Vol. 81, pp. 207-12.

Sala, F. (2002), Emotional Competence Inventory: Technical Manual, The Hay Group, Boston.

Suess, G.J., Grossmann, K.E. and Sroufe, L.A. (1992), "Effects of infant attachment to mother on quality of adaptation in preschool: from dyadic to individual organization of self", International Journal of Behavioral Development, Vol. 15, pp. 43-65.

Suleman, Q., Hussain, I., Syed, M.A., Parveen, R., Lodhi, I.S. and Mahmood, Z. (2019), “Association between emotional intelligence and academic success among undergraduates: a cross-sectional study in KUST, Pakistan”, PloS One, Vol. 14 No. 7, e0219468.

Truc, T.T., Loan, K.X., Nguyen, N.D., Dixon, J., Sun, J. and Dunne, M.P. (2015), "Validation of the educational stress scale for adolescents (ESSA) in Vietnam", Asia-Pacific Journal of Public Health, Vol. 27 No. 2, pp. NP2112-NP2121.

Uzzaman, M.A. and Karim, A.R. (2017), "Emotional intelligence scale: assessing its psychometric characteristics in Bangladeshi culture", The International Journal of Indian Psychology, Vol. 4 No. 2, pp. 86-87.

Volery, T. and Lord, D. (2000), "Critical success factors in online education", International Journal of Educational Management. doi: 10.1108/09513540010344731 (accessed 21 May 2020).

Zhang, H., Tao, F. and Zeng, G. (2001), "Depression and its correlates among middle school students in Anhui province", Chinese Journal of School Health, Vol. 22, pp. 497-498.

\section{Corresponding author}

Yamini Chandra can be contacted at: yaminichandra23@gmail.com

For instructions on how to order reprints of this article, please visit our website:

www.emeraldgrouppublishing.com/licensing/reprints.htm

Or contact us for further details: permissions@emeraldinsight.com 